\title{
TERAPI MOTORIK HALUS DENGAN SUNGGING
}

\author{
Bayu Asri, Jaka Triwiyana, dan Muhammad Vicky Solihin \\ Fakultas Seni Rupa dan Desain Institut Seni Indonesia Surakarta \\ email: bayuasri06@gmail.com
}

\begin{abstract}
Abstrak: Terapi Motorik Halus dengan Sungging. Permasalahan yang dihadapi yaitu sulitnya melakukan aktivitas gerakan otot kecil yang melibatkan mata, tangan, dan fokus. Penerapan pelatihan menggunakan pendekatan ekspresi bebas yaitu dengan menggambar pola garis dan titik (nirmana), mengolah warna dengan cat, dan melukis di atas kanvas sesuai imajinasi. Teknik sungging memenuhi berbagai aspek pengembangan motorik halus, yaitu: (1) membuat tingkatan gradasi warna memerlukan fokus, ketelitian, dan kecermatan dalam mencampur serta menggorekan cat untuk menghasilkan warna yang harmoni; (2) menggambar garis dan titik pola secara teratur menggunakan pensil untuk melatih ketangkasan, fokus, dan ketelitian; (3) mengolah campuran warna dengan cat sehingga menghasilkan berbagai warna gradasi untuk melatih kepekaan dan kecermatan; dan (4) menggoreskan kuas saat melukis untuk melatih imajinasi, kreativitas, serta koordinasi antara mata dengan gerakan tangan. Hasil pelatihan yaitu kemampuan motorik halus penyandang tuna grahita berkembang sehingga menjadi aktif dalam bergerak, terampil, teliti, dan berintelegensi.
\end{abstract}

Kata kunci: tuna grahita, melukis, terapi, motorik halus

\begin{abstract}
Fine Motor Skills Therapy through Sungging Technique. The problem faced was the difficulty of small muscle involving the eyes, hands to move or focus. The implementation of the training using free expresion method was done by drawing a pattern of lines and dots (nirmana), processing colors with paint, and painting on canvas. Sungging method met various aspects of fine motor development such as in (1) making a gradation color levels which require focus, precision, and accuracy in mixing and correcting the paint to produce a color harmony; (2) drawing lines and dot patterns regularly using pencil to train agility, focus and precision; (3)processing the mixture of colors with paint so as to produce various color gradations to train sensitivity and accuracy; (4) scraping brush when painting to train the imagination, creativity, as well as the coordination between the eyes with hand gestures. The results show the improvement of their mobile, skill, conscientious, and intelligence.
\end{abstract}

Keywords: down syndrome, painting, therapy, soft motoric

\section{PENDAHULUAN}

Anak Berkebutuhan Khusus (ABK) merupakan anak yang mengalami cacat tubuh, kelainan gangguan fisik, mental, intelektual, psikologis, sosial dan neurologis. Umumnya kelainan tersebut dibawa sejak lahir, bagi anak yang lahir tidak normal (divakum) atau kondisi 
fisiknya lemah, sehingga memerlukan bantuan dan latihan khusus. Suharso 2005: 98) menjelaskan bahwa:

"Cacat tubuh merupakan kerusakan pada tubuh seseorang, baik badan maupun anggota badan, baik kehilangan fisik, ketidaknormalan bentuk maupun berkurangnya fungsi karena bawaan sejak lahir atau karena penyakit dan gangguan lain semasa hidupnya sehingga timbul keterbatasan yang nyata untuk melaksanakan tugas hidup dan penyesuaian diri."

Munzayanah (2000: 13) menyatakan bahwa "Anak tuna grahita sebagai anak yang mengalami gangguan atau hambatan dalam perkembangan daya pikir serta seluruh kepribadian, sehingga ia tidak mampu hidup dengan kekuatan sendiri dalam masyarakat meskipun dengan cara sederhana Hal ini dapat dikaitkan dengan pernyataan dua orang peneliti yang menyatakan, "Seseorang dinyatakan tuna grahita apabila; terhambatnya atau memiliki fungsi kecerdasan dibawah rata-rata, tidak mampu berperilaku adaptif, terjadi selama perkembangan sampai usia 18 tahun" (Yusuf, Choiri, \& Subagya, 2009: 56).

Menurut Soemantri (2006) tuna grahita adalah anak dengan kemampuan intelektual di bawah rata-rata yang menyebabkan mereka sukar mengikuti program pendidikan di sekolah biasa, sehingga perlu pendidikan khusus sesuai kemampuan. Dari penjelasan para ahli tersebut dapat disimpulkan bahwa gangguan motorik halus (gangguan perkembangan intelektual) adalah gangguan yang terjadi selama periode perkembangan yang meliputi terganggunya fungsi intelektual dan fungsi adaptif pada ranah konsep, sosial dan praktik bina diri yang rendah.
Aktivitas motorik dibagi menjadi dua, yaitu motorik kasar dan motorik halus. Dalam kaitannya dengan penyandang tuna grahita, perkembangan motorik halus lebih diutamakan untuk dikuasai karena mereka kesulitan untuk mengontrol gerakan kecil, kurang fokus, dan kemampuan berpikirnya rendah.

Motorik halus merupakan kegiatan yang menggunakan otot-otot halus pada jari dan tangan. Menurut Nursalam (2005) perkembangan motorik halus adalah kemampuan anak untuk mengamati sesuatu dan melakukan gerakan yang melibatkan bagian-bagian tubuh tertentu dan otototot kecil, memerlukan koordinasi yang cermat serta tidak memerlukan banyak tenaga. Terapi motorik bisa dilakukan dengan cara melatih memegang benda kecil secara sempurna, membuka tutup botol, meremas kertas, menjumput bijibijian, dan lain sebagainya. Namun terapi motorik yang mengkombinasikan gerakan koordinasi otot-otot kecil, kreativitas, dan pola pikir untuk memecahkan masalah yang dilakukan secara bersamaan saat ini belum dikembangkan. Sehingga terapi motorik halus yang ada sebelumnya cenderung membosankan dan kurang efektif.

Masalah yang mendasari diadakannya penelitian ini adalah belum adanya metode terapi motorik yang memadukan antara terapi dengan kegiatan yang mampu merangsang koordinasi otot-otot kecil sekaligus merangsang kreativitas dan imajinasi secara bersamaan. Penelitian ini dilakukan untuk mengetahui metode yang tepat digunakan sebagai terapi motorik halus yang efektif sekaligus kreatif bagi penyandang tuna grahita. Hasil dari penelitian bisa diterapkan kepada seluruh penyandang tuna grahita baik di sekolah maupun di rumah. 


\section{METODE}

Penelitian ini menggunakan metode kualitatif dengan pendekatan deskriptif. Menurut Williams dan Ellis (1995) seperti yang dikutip dari Moleong (2007: 05) mengemukakan bahwa penelitian kualitatif adalah pengumpulan data pada suatu latar alamiah dengan menggunakan metode alamiah, dan dilakukan oleh orang atau peneliti yang tertarik secara alamiah. Penelitian kualitatif bertujuan untuk memperoleh gambaran seutuhnya melalui proses yang berhubungan dengan ide, persepsi, pendapat atau kepercayaan menurut pandangan manusia yang diteliti. Menurut Sugiyono (1994) penelitian deskriptif merupakan penelitian yang dilakukan terhadap variabel mandiri, yaitu tanpa meembuat perbandingan atau menghubungkan dengan variabel yang lain. Variabel dalam penelitian ini merupakan variabel tunggal, yaitu motorik halus. Artinya penelitian ini memaparkan hasil kemajuan terapi motorik halus melalui proses pelatihan dengan metode melukis menggunakan teknik sungging terhadap sampling yaitu penyandang tuna grahita SLB Panca Bhakti Mulia Surakarta.

Dari observasi yang dilakukan terhadap sampel Anak Berkebutuhan Khusus penyandang tuna grahita SLB Panca Bhakti Mulia Surakarta, pelatihan yang cocok diterapkan yaitu menggunakan metode terapi melukis. Terapi melukis dipilih karena dalam pelaksanaan melibatkan koordinasi otot-otot jari tangan dengan otak dan mata antara lain memegang pensil, menuangkan cat ke dalam palet, menggoreskan kuas, dan berimajinasi. Selain itu, metode melukis merupakan terapi motorik halus yang murah, mudah diterapkan, dan bisa dilakukan kapan saja sehingga mampu merangsang kreativitas, ketelitian, dan pola pikir dalam memecakan masalah.
Terapi melukis yang diterapkan menggunakan teknik sungging. Sungging yaitu istilah yang berkembang pada budaya Jawa, khususnya pada teknik penerapan warna dalam pembuatan wayang kulit. Menurut Poerwadarminta (1976), sungging artinya seni menggambar perhiasan berwarna dengan cat (air mas dan sebagainya). Sungging merupakan jenis teknik dalam mengolah warna pada bidang dwi matra maupun tri matra. Berdasarkan istilah tersebut, sungging mempunyai ciri khas yaitu penerapan beragam warna dengan susunan warna bertingkat atau bergradasi dari warna muda ke tua, warna ringan ke berat, warna terang ke gelap, dan sebaliknya. Dewasa ini teknik sungging tidak hanya diterapkan pada kulit saja, namun berkembang dan diterapkan pada wayang beber (kain), lukis kaca, kriya kayu, interior dan eksterior ruangan.

Teknik sungging tidak lepas dengan warna, karena warna merupakan bahan, unsur, wujud atau hasil dari sunggingan. Warna merupakan unsur seni rupa yang menampakkan perbedaan penampilan, raut dan kualitas wujud permukaan antar bidang satu dengan yang lain serta bisa menggambarkan makna dan simbol suatu obyek dan sifat secara nyata. Warna sangat berperan dalam aspek kehidupan manusia karena diterapkan pada benda sehari-hari, antara lain pakaian, perhiasan, rumah, perabotan, bungkus, makanan, permainan, karya seni, dan sebagainya.

Dalam penerapannya sebagai terapi motorik halus, teknik sungging memenuhi berbagai aspek pengembangan motorik halus. Membuat tingkatan gradasi warna memerlukan fokus, ketelitian dan kecermatan dalam mencampur dan menggoreskan cat untuk menghasilkan warna yang harmoni. Menggambar garis dan titik pola secara teratur menggunakan 
pensil untuk melatih ketangkasan, fokus dan ketelitian. Mengolah campuran warna dengan cat sehingga menghasilkan berbagai warna untuk melatih kepekaan dan kecermatan. Menggores kuas saat melukis untuk melatih imajinasi, kreativitas, serta koordinasi antara mata dengan gerakan tangan.

Dalam pelaksanaaan pelatihan melukis menggunakan pendekatan ekspresi bebas. Menurut Nanang Ganda Prawira (1997) pendekatan ekspresi bebas adalah pendekatan dimana peserta bebas untuk bereksplorasi dan bereksperimen dalam melukis sesuai keinginan dan cara mereka sendiri. Tujuannya supaya para peserta mampu menggali ide dan menciptakan inovasi dalam melukis serta meningkatkan skills motorik halus mereka, sehingga menghasilkan karya yang bervariasi sesuai dengan gaya dan aliran masingmasing individu. Dalam mengaplikasikan pendekatan ekspresi bebas dengan metode melukis menggunakan teknik sungging, diperlukan ketelitian, ketepatan, ketangkasan, perhitungan, dan keterampilan tangan dalam mengolah, mencampur, dan menggoreskan cat pada kanvas.

Dalam menerapkan terapi motorik halus dengan metode melukis menggunakan teknik sungging, pelatihan diterapkan selama empat pertemuan dari tanggal 14 April - 12 Mei 2016 bertempat di ruang serbaguna SLB Panca Bhakti Mulia Surakarta. Pelatiha dibagi menjadi empat tahapan. Tahap melukis dengan teknik sungging yaitu menggambar pola garis dan titik, mengolah warna, melukis sungging, dan finishing. Alat dan bahan yang digunakan antara lain kertas HVS ukuran A4, pensil, penghapus, cat acrylic, kuas, palet, kanvas ukuran 20 × $20 \mathrm{~cm}$, dan semprotan clear.
Pelatihan tahap pertama diadakan pada tanggal 14 April 2016. Peserta diajarkan menggambar garis dan bidang secara teratur dan berulangulang menggunakan pensil di selembar kertas ukuran A4. Pelatihan menggambar menggunakan nirmana garis sebagai salah satu dasar teknik sungging secara teratur dan berulang-ulang berujuan untuk melatih koordinasi antara otak, mata, dan tangan supaya bisa fokus dan teliti dalam menggambar. Pelatihan menggambar nirmana digunakan sebagai dasar penilaian kemajuan motorik peserta sebagai pembanding dengan hasil tahap berikutnya.

Pelatihan tahap kedua diadakan tanggal 21 April 2016, yaitu kegiatan mengolah warna. Para peserta diajarkan mencampur warna primer menggunakan cat acrylic dengan warna dasar putih, hitam, merah, biru, dan kuning. Dengan mengolah campuran warna primer akan menghasilkan warna sekunder seperti hijau, ungu, jingga, merah muda, dan cokelat. Warna hitam dan putih digunakan sebagai campuran sehingga menghasilkan tingkatan warna gelap dan terang sesuai dengan pola dasar tingkatan warna teknik sungging. Tujuan melatih mengolah warna yaitu merangsang kepekaan akan warna dasar dan takaran sehingga menghasilkan warna baru dan tingkatan gradasi warna yang harmoni. Mentor juga mengajarkan cara memegang kuas dengan benar saat menggoreskan cat yang bertujuan untuk melatih jari dan tangan supaya kuat dan terampil dalam memegang benda-benda kecil.

Pelatihan tahap ketiga dilaksanakan tanggal 28 April 2016, yaitu kegiatan melukis menggunakan teknik sungging diatas kanvas berukuran $20 \times 20 \mathrm{~cm}$ dengan pendekatan ekspresi bebas 
sehingga peserta bebas melukis sesuai imajinasi masing-masing. Para peserta membuat sketsa gambar di atas kanvas menggunakan pensil, lalu mulai mewarnai dengan tingkatan warna menggunakan kuas dan cat acrylic. Tujuan melatih melukis di atas kanvas yaitu supaya peserta mampu mengaplikasikan berbagai tahapan dalam melukis menggunakan teknik sungging mulai dari menggambar sketsa, mencampur warna, dan melukis secara bersamaan.

Pelatihan tahap keempat diadalkan tanggal 12 Mei 2016,yaitu kegiatan finishing hasil lukisan. Lukisan yang sebelumnya belum selesai disempurnakan dalam pertemuan ini, yaitu dengan menambahkan outline/garis tepi gambar dan titik-titik sesuai dasar teknik sungging. Lukisan yang selesai dibuat diberi lapisan semprotan clear supaya cat tidak mengelupas dan mampu bertahan lama.

\section{HASIL DAN PEMBAHASAN}

Pelatihan terapi motorik halus dengan metode melukis menggunakan teknik sungging mampu menghasilkan kemajuan aktivitas motorik penyandang tuna grahita. Dari hasil pelatihan tahap pertama, peserta belum mampu menggambar garis yang konstan dengan sempurna. Garis yang dihasilkan tidak urut dan bentuknya tidak sama satu dengan yang lain. Setelah beberapa kali percobaan dengan bimbingan mentor, peserta mulai mampu menggambar garis berulangulang secara teratur dan sama. Dengan menghasilkan pola gambar yang teratur maka peserta mulai bisa mengendalikan emosi serta koordinasi mata dan tangan dengan baik (Gambar 1).

Setelah pelatihan menggambar garis, peserta dilatih mencampur warna menggunakan cat acrylic. Peserta kesulitan dalam mengolah dan mencampur warna karena tangan tidak bisa cekatan dalam menuangkan cat. Sehingga campuran warna banyak yang kurang pas, yaitu terlalu gelap namun juga terlalu terang. Setelah diarahkan oleh mentor dan berlatih mencampur warna dengan tenang dan hati-hati,

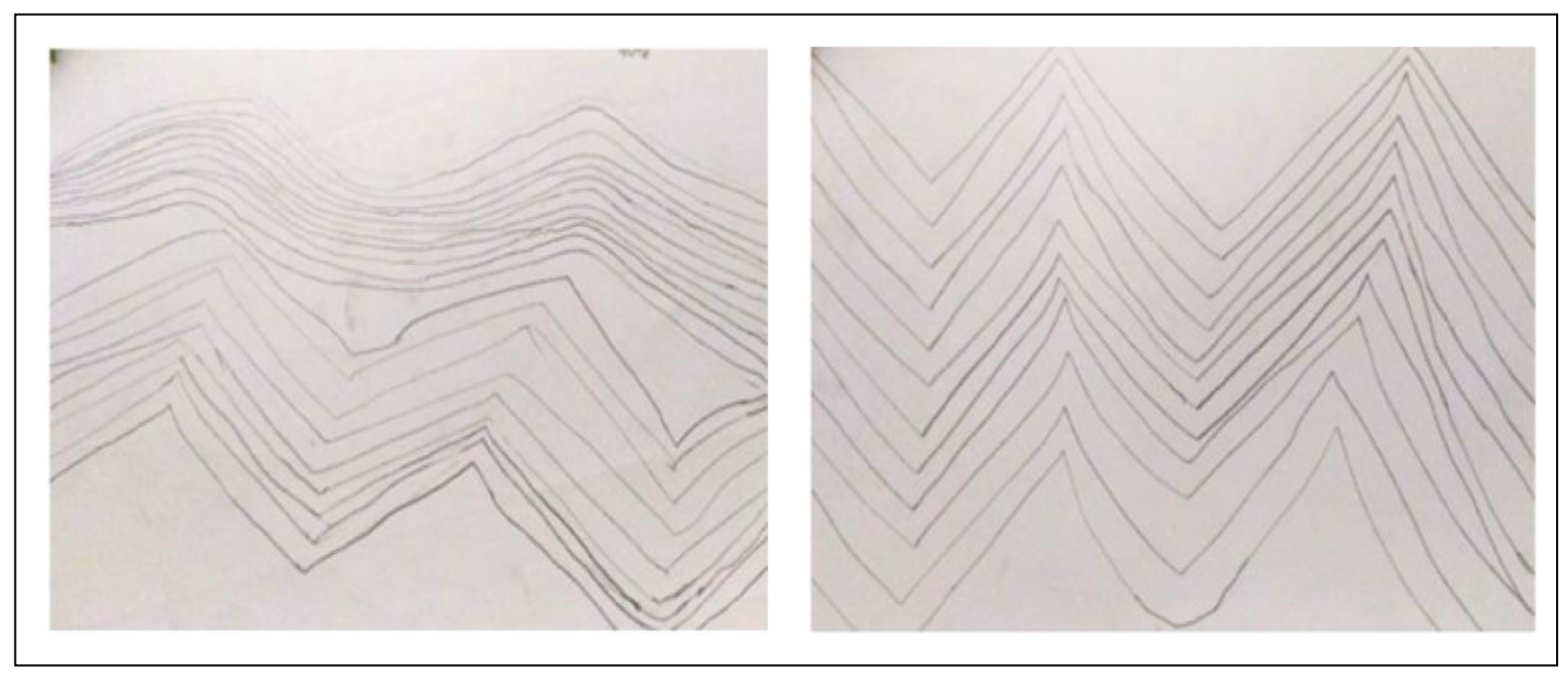

Gambar 1. Hasil Gambar Garis Semula Tak Beraturan Menjadi Semakin Beraturan (Sumber: Dokumentasi Pribadi) 
peserta akhirnya bisa memperoleh tingkatan gradasi warna yang sesuai dengan harapan. Dengan cara ini peserta menjadi cermat, peka dan teliti dalam mencampur warna sehingga koordinasi antara mata, otak, dan tangan akan menghasilkan warna yang pas.

Peserta lalu praktik melukis di atas kanvas menggunakan teknik sungging setelah berhasil menggambar garis pola secara teratur dan menguasai tingkatan gradasi warna. Dalam melukis menggunakan teknik sungging, membuat gambar mampu mengembangkan imajinasi, pola pikir, dan gerakan motorik tangan dalam menggoreskan kuas. Sedangkan membuat gradasi tingkatan warna mampu mengembangkan ketelitian, kesabaran, kecermatan, dan kemampuan emosional peserta (Gambar 2).

Peserta mampu menjalankan terapi melukis sungging dengan baik. Saraf motorik halus mulai terangsang dan terasah setelah melakukan kegiatan melukis. Koordinasi antara mata sebagai sumber informasi, otak sebagai pusat berpikir, mengolah informasi dan berimajinasi, serta tangan sebagai motor penggerak hasil berpikir akan berjalan dengan optimal sesuai tujuan pelatihan.

Tahap terakhir yaitu finishing dengan menambahkan outline/garis tepi gambar dan titik-titik sesuai dasar teknik sungging. Dalam membuat garis di tepi gambar dan titik-titik menggunakan spidol, peserta mampu mengembangkan imajinasi dan kreativitas untuk memperindah hasil lukisan. Menyemprot lukisan dengan pelapis clear supaya lukisan tahan lama juga melatih koordinasi otat jari tangan supaya menghasilkan semprotan yang rata (Gambar 3).

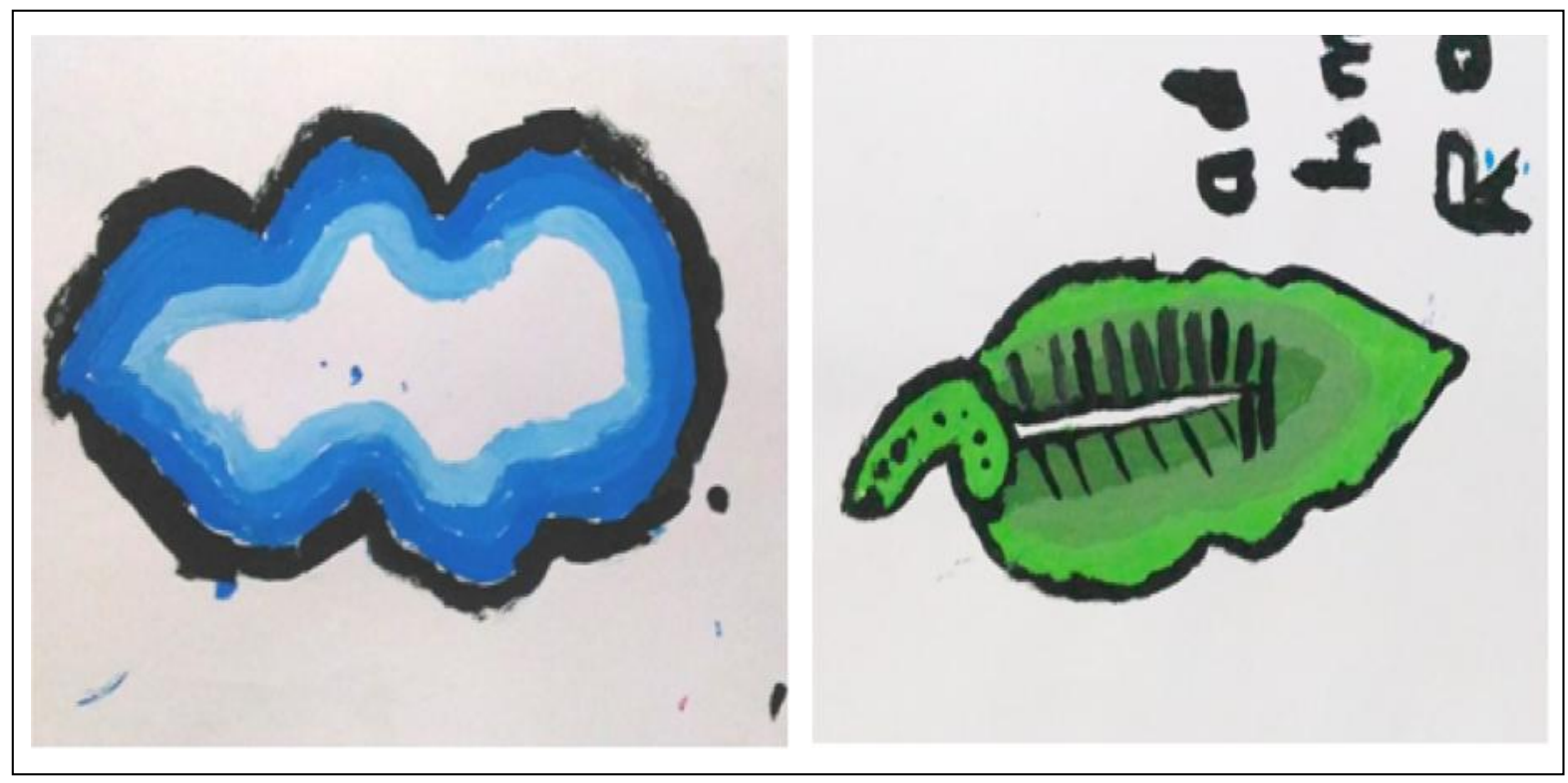

Gambar 2. Hasil Pengolahan Warna dengan Teknik Sungging

(Sumber: Dokumentasi Pribadi) 


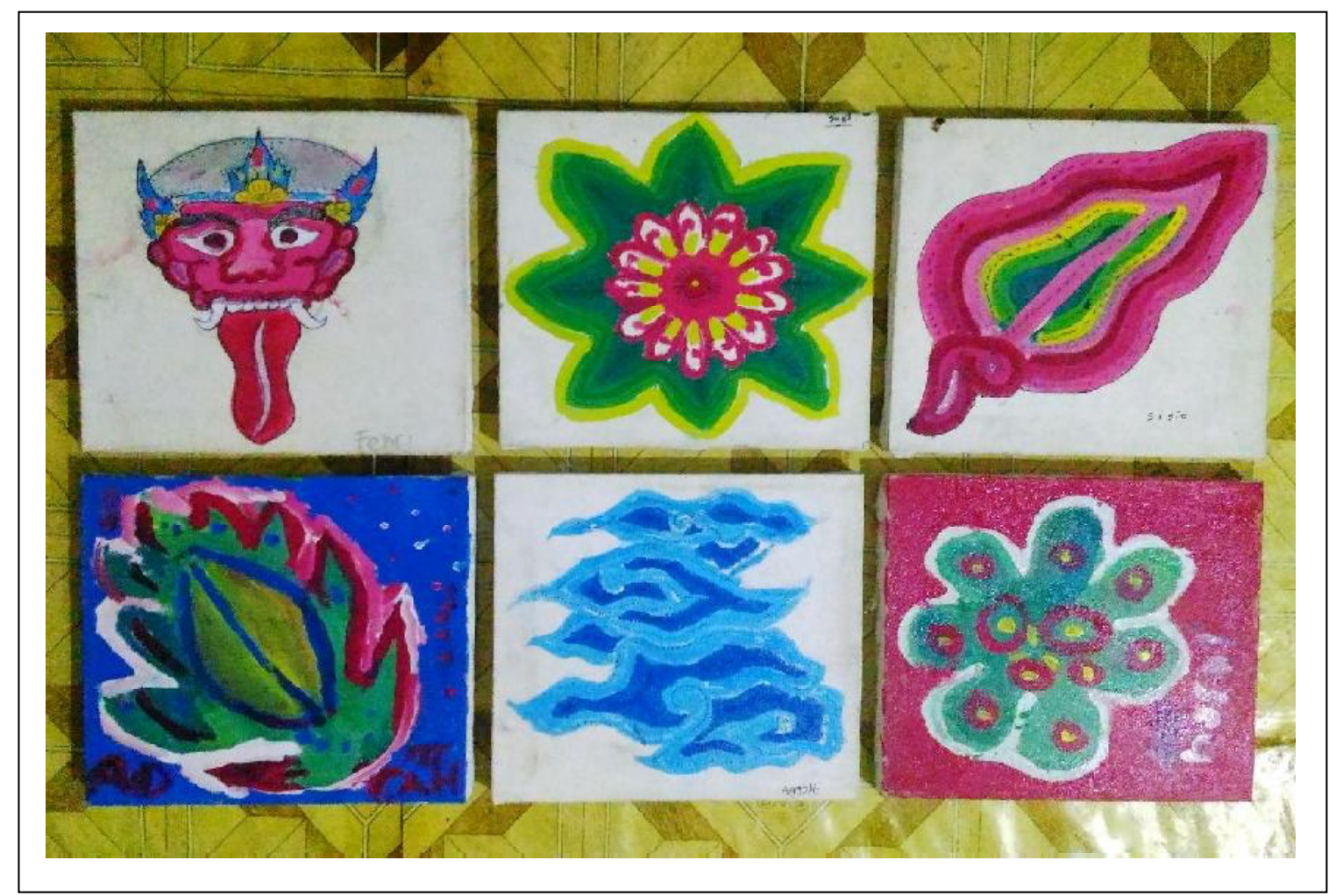

Gambar 3. Hasil Lukisan Teknik Sungging Tuna Grahita (Sumber: Dokumentasi Pribadi)

\section{SIMPULAN}

Perkembangan motorik halus adalah kemampuan anak untuk mengamati sesuatu dan melakukan gerakan yang melibatkan bagian-bagian tubuh tertentu dan otot-otot kecil, memerlukan koordinasi yang cermat serta tidak memerlukan banyak tenaga. Motorik halus bagi penyandang tuna grahita dapat dilatih melalui terapi melukis menggunakan teknik sungging. Teknik lukis sungging memenuhi berbagai aspek pengembangan motorik halus. Menggambar garis dan titik-titik pola secara teratur menggunakan pensil untuk melatih ketangkasan, fokus dan ketelitian. Membuat tingkatan gradasi warna yang harmoni dengan mengolah campuran warna primer menjadi warna sekunder berguna untuk melatih kepekaan, fokus, ketelitian dan kecermatan. Menggoreskan kuas di atas kanvas saat melukis berguna untuk melatih imajinasi, kreativitas, serta koordinasi antara mata dengan gerakan tangan.

Pada kesempatan ini saya mengucapkan terima kasih kepada Allah SWT yang melimpahkan hidayah dan petunjuk-Nya sehingga penulis mampu menyelesaikan penelitian ini dengan lancar. Ucapan terima kasih ditujukan kepada Asmoro Nurhadi Panindias, S.Sn, M.Sn selaku dosen pembimbing dalam penelitian ini. Ucapan terima kasih ditujukan kepada Kemenristekdikti yang telah memberikan bantuan modal guna terselenggaranya penelitian ini. Ucapan terima kasih ditujukan kepada seluruh 
civitas akademik Institut Seni Indonesia Surakarta yang memberi sarana dan prasarana untuk kegiatan penelitian ini. Ucapan terima kasih ditujukan kepada Drs. Suharno, M.Pd, selakun kepala Sekolah Luar Biasa Panca Bakti Mulia Surakarta dan para peserta didik Sekolah Luar Biasa Panca Bakti Mulia Surakarta yang bersedia digunakan sebagai sampel penelitian. Ucapan terima kasih ditujukan kepada rekan mahasiswa Program Studi Desain Komunikasi Visual Institut Seni Indonesia Surakarta yang membantu pelaksanaan penelitian ini.

\section{DAFTAR PUSTAKA}

Prawira, N. G. 1997. Seni Rupa dan Pendidikan. Bandung: PGSD.

Moleong, L. J. 2007. Metodologi Penelitian Kualitatif. Bandung: Remaja Rosdakarya.
Munzayanah. 2000. Tuna grahita. Surakarta: Jurusan Ilmu Pendidikan, Fakultas Keguruan dan Ilmu Pendidikan, Universitas Sebelas Maret.

Nursalam, 2005. Asuhan Keperawatan Bayi dan Anak. Jakarta: Salemba Medika.

Somantri, S. 2006. Psikologi Anak Luar Biasa. Bandung: PT. Refika Aditama

Sugiyono. 1994. Metode Penelitian Administrasi. Bandung: Alfabeta.

Suharso, A. R. 2005. Kamus Besar Bahasa Indonesia. Semarang: Widya Karya.

Williams, D., \& Ellis, J. 1995. International Business Strategy. London: Pitman.

Yusuf, M., Choiri, A. S., \& Subagya. 2013. Pendidikan Kompensatoris Anak Berkebutuhan Khusus (ABK). Surakarta: Konsorsium Sertifikasi Guru. Diunduh dari http://sertifikasi. fkip.uns.ac.id._30 Desember 2015. 